\title{
QUEEN'S
UNIVERSITY
BELFAST
}

\section{Computer-aided drug discovery of Myc-Max inhibitors as potential therapeutics for prostate cancer}

Carabet, L. A., Lallous, N., Leblanc, E., Ban, F., Morin, H., Lawn, S., Ghaidi, F., Lee, J., Mills, I. G., Gleave, M. E., Rennie, P. S., \& Cherkasov, A. (2018). Computer-aided drug discovery of Myc-Max inhibitors as potential therapeutics for prostate cancer. European journal of medicinal chemistry, 160, 108-119.

https://doi.org/10.1016/j.ejmech.2018.09.023

Published in:

European journal of medicinal chemistry

Document Version:

Peer reviewed version

Queen's University Belfast - Research Portal:

Link to publication record in Queen's University Belfast Research Portal

\section{Publisher rights}

Copyright 2018 Elsevier.

This manuscript is distributed under a Creative Commons Attribution-NonCommercial-NoDerivs License

(https://creativecommons.org/licenses/by-nc-nd/4.0/), which permits distribution and reproduction for non-commercial purposes, provided the author and source are cited.

\section{General rights}

Copyright for the publications made accessible via the Queen's University Belfast Research Portal is retained by the author(s) and / or other copyright owners and it is a condition of accessing these publications that users recognise and abide by the legal requirements associated with these rights.

Take down policy

The Research Portal is Queen's institutional repository that provides access to Queen's research output. Every effort has been made to ensure that content in the Research Portal does not infringe any person's rights, or applicable UK laws. If you discover content in the Research Portal that you believe breaches copyright or violates any law, please contact openaccess@qub.ac.uk. 


\title{
Computer-aided drug discovery of Myc-Max inhibitors as
}

\section{potential therapeutics for prostate cancer}

Lavinia A. Carabet ${ }^{\mathrm{a}, \mathrm{c}}$, Nada Lallous ${ }^{\mathrm{a}, \mathrm{c}}$, Eric Leblanc ${ }^{\mathrm{a}}$, Fuqiang Ban ${ }^{\mathrm{a}}$, Helene Morin ${ }^{\mathrm{a}}$, Sam Lawn ${ }^{\text {a }}$, Fariba Ghaidi ${ }^{\text {a }}$ Joseph Lee ${ }^{\mathrm{a}}$, Ian G. Mills ${ }^{\mathrm{b}, \mathrm{e}}$, Martin E. Gleave ${ }^{\mathrm{a}}$, Paul S.

Rennie $^{\mathrm{a}, \mathrm{d}}$, and Artem Cherkasov ${ }^{\mathrm{a}, \mathrm{d}, *}$

${ }^{a}$ Vancouver Prostate Centre, University of Britich Columbia, 2660 Oak Street, Vancouver, British Columbia V6H 3Z6, Canada

${ }^{b}$ Centre for Cancer Research and Cell Biology, Queen's University, Belfast, United Kingdom

${ }^{c}$ Co-first authors

${ }^{d}$ Dr. Cherkasov's and Dr. Rennie's laboratories made equal contributions to this work

e Nuffield Department of Surgical Sciences, John Radcliffe Hospital, University of Oxford, Oxford, United Kingdom

\begin{abstract}
While Myc is an essential regulator of growth in normal cells, it is also frequently associated with cancer progression, therapy-resistance and lethal outcomes in most human cancers. In prostate cancer (PCa), Myc transcription factors are implicated in the pathogenesis and progression of the full spectrum of PCa, from adenocarcinoma to advanced castrationresistant and neuroendocrine phenotypes. Though a high-value therapeutic target, clinically approved anti-Myc drugs have yet to be discovered. To elicit its oncogenic effects, Myc must form a heterodimer with its partner Max, which together bind DNA and activate transcription of a spectrum of target genes that promote cell growth, proliferation, metabolism,
\end{abstract}

* Corresponding author: Artem Cherkasov, Vancouver Prostate Centre, 2660 Oak Street, Vancouver, British Columbia V5H 3Z6, Canada. Tel.: 604-875-4111; Fax: 604-875-5654.

E-mail address: acherkasov@prostatecentre.com 
apoptosis and block differentiation. In this study, we identified a binding site on the DNA-binding domain of the structurally ordered Myc-Max complex and employed a computer-aided rational drug discovery approach to identify small molecule binders that effectively inhibit Myc-Max functionality. A large-scale virtual screening protocol implementing structure-based methodologies was utilized to select a set of top-ranked compounds that were subsequently evaluated experimentally and characterized mechanistically for their ability to inhibit Myc-Max transcriptional activity and subsequent downstream functions, to reduce viability in PCa cell lines, disrupt protein-DNA interactions and to induce apoptosis as their mechanism of action. A number of compounds was identified that effectively inhibit Myc-Max activity with low micromolar potency and no apparent generic cytotoxicity. Among these, VPC-70067, a close analog of the previously identified Myc inhibitor 10058-F4, serves as proof-of-concept that the in silico drug discovery strategy employed in this work performs as expected. Compound VPC-70063, of a chemically different scaffold, is the best performer in a panel of cell-based and in vitro assays, and the forerunner for future hit-to-lead optimization efforts. These findings lay a foundation for developing more potent, specific and clinically optimized Myc-Max inhibitors that may serve as promising far-reaching therapeutics, alone or in combination with current anti-PCa treatments, for effective, potentially curative treatment of specific phenotypes or heterogeneous tumors in PCa patients.

Keywords: Myc-Max; prostate cancer; computer-aided drug discovery; small molecule inhibitors; protein-DNA interactions.

\section{Introduction}

Myc is an essential regulator of growth in normal cells, but in many cancers this transcription factor is overactive to support high rates of growth needed for tumor maintenance and progression [1, 2]. Myc drives tumorigenesis by transcriptional programming of a large number of target genes that promote cell growth, proliferation, metabolism and apoptosis, and block differentiation [3-7]. Myc is estimated to contribute to most if not all human cancers, including prostate, breast, colon, cervical cancers, small-cell lung carcinomas, neuroblastomas, osteosarcomas, glioblastomas, melanoma, and myeloid leukaemia, most of which are aggressive and respond poorly to the current therapies $[1,8,9]$. 
In prostate cancer $(\mathrm{PCa})$, which is the second leading cause of cancer-related death in men, Myc family members - L-Myc, c-Myc and N-Myc - are implicated in pathogenesis and progression of the full spectrum of $\mathrm{PCa}$, ranging from adenocarcinoma to the most advanced and lethal subtypes - castration-resistant (CRPC) and its neuroendocrine phenotype (NEPC). Amplifications of Myc family members are the most frequently observed genomic alterations associated with specific clinical stages and subtypes of PCa [10-16]. L-Myc is amplified in $27 \%$ of localized PCa, in a mutually exclusive manner to c-Myc [11], whereas c-Myc is commonly amplified in all PCa stages and subtypes [17]. Notably, c-Myc overexpression antagonizes the transcriptional activity of the androgen receptor (AR), which is a driving force in $\mathrm{PCa}$ and constitutes the main drug target for advances cases of disease [18]. Besides influencing clinically relevant AR target genes, c-Myc upregulation also affects critical splicing programs [19] and increases levels of AR-V7 - the constitutively active ligand-independent AR splice variant that promotes CRPC [20, 21] and is also observed in NEPC [14]. Importantly, N-Myc amplifications induce the NEPC phenotype [14, 15, 22].

To elicit its oncogenic effects, Myc must form a heterodimer with its obligate partner Max, which together bind to the DNA and activate transcription of the target genes [23-26]. Although Myc could qualify as an ideal cancer target, applying conventional structure-based drug design approaches represents an inherent challenge in drugging Myc. Myc and Max are intrinsically disordered proteins (IDP) which exist as dynamic ensembles, with no effective pockets on their surfaces [27-29]. The disordered basic-helix-loop-helix-leucine zipper (bHLHLZ) domain of the Myc monomer forms DNA-binding functionalities only via association with the homologous bHLHLZ domain of Max [23, 30]. Only upon such heterodimerization does the resulting MycMax complex adopt a stable helical configuration which can bind specific DNA recognition sequences 5'CACGTG-3', termed E-boxes, at enhancers and promoters of target genes, and thereby trigger the recruitment of chromatin-remodeling complexes and assembly of the transcriptional machinery to drive the transcriptional program [31, 32]. Myc and Max oligomerize through their helix-loop-helix (HLH) and leucine zipper (LZ) 
regions and bind DNA mainly through highly positively charged basic (b) region and specific residues located in the HLH region [33, 34].

Although Myc inactivation may have undesired effects on normal cells, experimental mouse models of KRas-driven lung cancer carrying a conditionally inducible Omomyc construct - a Myc dominant negative, 93 residue bHLHZ protein fragment with 4 single-point mutations in the LZ region - have established that periodic inhibition is very effective at stopping cancer growth, while resulting in mild and tolerable side effects, suggesting a viable therapeutic strategy $[35,36]$.

Small molecule inhibition of Myc, a therapeutically compelling oncogenic transcription factor, has been a challenge for a long time. Current strategies that directly target Myc in cancer include inhibitors of Myc-Max protein-protein interactions, such as 10058-F4, 10074-G5, and JY-3-094 [37, 38], or protein-DNA interactions, such as Mycro3 [39] and KJ-Pyr-9 [40], and inhibitors of Myc expression with G-quadruplex stabilizers, antisense oligonucleotides, and siRNA [41, 42]. Indirect approaches have been reviewed elsewhere $[41,43,44]$.

Compounds 10058-F4, 10074-A4, and 10074-G5 are among the first identified direct small molecules Myc inhibitors that bind with low micromolar affinity at 3 independent sites on the disordered bHLHLZ domain of the Myc (c- and N-Myc) monomer (as validated by mutagenesis and NMR experiments) [37, 45, 46]. The efforts to identify them relied on functional screening of finite libraries unlikely to contain clinicallyoptimized structures. Attempts to find more potent and selective analogs generally failed given the inconsistent behavior of compounds in cell-based and in vitro assays [47, 48]. Moreover, these compounds lack proper antitumor activity in vivo due to rapid metabolism to inactive metabolites, resulting in low concentrations in tumors insufficient to inhibit Myc-Max dimerization in vivo $[49,50]$. Thus, the quest for discovering effective small molecule inhibitors of Myc is under way and several groups are actively pursuing this research. 


\section{Results and Discussion}

In this study, we identified a binding site on the DNA-binding domain (DBD) of the structurally ordered Myc-Max complex and employed a computer-aided drug discovery approach to identify small molecules binders that inhibit Myc-Max activity. A large-scale virtual screening protocol implementing structure-based methodologies was utilized to select a set of top-ranked compounds that were subsequently evaluated experimentally for their effect in inhibiting Myc-Max transcriptional activity, suppressing subsequent downstream functions and their effect in reducing viability of various PCa cell lines. We have further characterized the identified compounds for their ability to bind Myc-Max directly, to disrupt protein-DNA interactions and to induce apoptosis as their mechanism of action. A number of prospective small molecules were identified that effectively inhibit Myc-Max activity with low micromolar potency and no generic cytotoxicity. Among these, on one hand, a compound 70067 highly similar in structure, potency and mechanism of action to 10058-F4 serves as proof-of-concept and validates the in silico drug discovery strategy employed in this work. On the other hand, compound 70063 of a different chemotype qualified as the best performer in a panel of cell-based and in vitro assays, and has been selected for our future optimization efforts based on observed structure activity relationships (SAR).

\subsection{Identification of potentially druggable surface sites on the Myc-Max DNA-binding domain (DBD). The} published $1.9 \AA$ A crystal structure of c-Myc-Max heterodimer bound to its DNA-recognition sequence (PDB ID: 1NKP) [34] was selected for identification of plausible pockets where small molecules may bind and disrupt the c-Myc-Max DBD - E-box complex. Using the Site Finder module of the Molecular Operating environment (MOE) suite of programs [51], one potential binding site was predicted at the Myc-Max-DNA interface. MOE's Site Finder is a geometric method used to calculate possible active sites in a receptor from its 3D atomic coordinates and rank the sites according to their Propensity for Ligand Binding (PLB) score based on the amino acid composition of the pocket. As the highest PLB-ranked pocket, the predicted binding 
site was considered for targeting the Myc-Max DBD with small molecules. The pocket is located at the fork formed between the DNA-binding bHLH regions of c-Myc and Max, with which the dimer inserts itself into the DNA major groove (Fig. 1A). This site identified on the ordered dimer interface contains highlyconserved residues from both Myc and Max monomers and as such differs from the previously reported sites on the Myc disordered monomer. The pocket (Fig. 1B) is shaped by hydrophobic residues Leu917 and Phe921 from the c-Myc monomer and the equivalent residues Ile218 and Phe222 from the homologous Max monomer, and charged residues Lys939 from c-Myc, and Arg212, Arg215, Asp216, Lys219 and Arg239 from Max (see also Fig. 4B, section 2.6 for further details). The functional relevance of residues in the site was demonstrated by evidences from Max-Max [33] and Omomyc [52] homodimers crystallographic studies. It has been demonstrated that Arg215 in the basic region of Max makes both base-specific and contacts with the phosphate groups of the DNA backbone, dictates the identity of the central 5'-CG-3' dinucleotide of the canonical E-box sequence, and appears to be essential for DNA binding. Similarly, Arg239 of Max makes side-chain and backbone amide contacts with phosphate groups of DNA backbone, tethers Helix-2 to DNA, and stabilizes the interactions between Helix-1 and Helix-2 by packing against Phe222 conserved hydrophobic residue in Helix-1. Arg239 is important for both dimerization and DNA binding. Lys939 of Myc, the counterpart of Arg239 of Max, makes specific contacts with phosphate groups of DNA backbone [33]. A recently reported comparison of the protein-DNA interface of Omomyc to that of the Myc-Max DNA complex [52] demonstrated that both complexes bind to the DNA major groove by forming a scissor-like structure at the E-box, and that the basic region of both complexes assume the same phosphate-backbone and base-specific contacts to DNA, an example of which is Arg914 of Myc (Arg20 of Omomyc), the equivalent of Arg215 of Max. Thus, the positively charged residues lining up the identified site may provide hydrogen bonding and/or salt bridges propensity for potential binders to disrupt the above-mentioned DNA base and phosphate contacts while the hydrophobic core of the site may substantially anchor the binders via 
hydrophobic interactions. Inhibitors targeting the predicted site are expected to block Myc-Max binding to DNA.

2.2. In silico identification of hit compounds targeting the Myc-Max DBD site. The drug-like subset of the ZINC12 molecular database [53, 54], containing more than 6 million purchasable chemicals, was further reduced to 4.7 million compounds by filtering by physicochemical properties such as charge, number of rings and rotatable bonds. The resulting set of 4.7 million structures was virtually screened against the identified pocket on the Myc-Max dimer DBD. Glide (Maestro 9.3 suite, Schrödinger LLC) software [55-57] was employed as the primary structure-based docking technique (with the standard precision mode). The generated docking poses were then filtered by the Glide docking score (binding energy score used to rank docking poses and distinguish strong binders in their optimal placement in the respective pocket from compounds that bind weakly) using a $-5.5 \mathrm{kcal} / \mathrm{mol}$ cutoff. The top ranked 12503 remaining compounds were further filtered by structure-based pharmacophore screening using MOE's tools. A pharmacophore model of two essential hydrophobic features (1.5 ^ diameter each) of the binding site (formed primarily by Leu917, Ile218, Phe921 and Phe222) was built and used to search for matching hits in the database of top ranked Glide poses (Fig. 1B and Fig. 4A). 1019 pharmacophore-matching hits were then selected for visual inspection. 116 compounds having a good balance of Glide docking score and ligand efficiency (the ratio of binding affinity over the number of heavy atoms) made additional side-chain or backbone hydrogen bonds with the charged residues in the site. 69 chemicals were selected for purchase, in particular those predicted to form hydrogen bonds with the backbone carbonyl oxygen of Arg215. The purchased compounds were then subjected to rapid evaluation using a primary screening transcriptional assay (see below). From the primary cell-based screening 10 hits were identified (Table 1) showing better than 50\% inhibition of Myc-Max transcriptional activity. Hits with more than $70 \%$ inhibition were investigated for the effect on the downstream pathway using UBE2C reporter assay. 
2.3. Effects of hit compounds on Myc-Max transcriptional activity. Compounds were subjected to experimental evaluation using the commercially available transcriptional assay Cignal c-Myc luciferase reporter assay in LNCaP cells. Compounds 10058-F4 and 10074-G5, known Myc inhibitors from the literature, were used as positive controls. A transiently transfected Myc-driven luciferase reporter allowed the monitoring of Myc-regulated signal LNCaP upon treatment with the in silico identified compounds. From a larger number of hits, 10 compounds caused more than 50\% reduction of the Myc-driven luciferase levels at $25 \mu \mathrm{M}$ (see Table 1). A thorough dose response analysis was performed using LNCaP cells to evaluate the potency of hit compounds. The compounds inhibit Myc-Max transcriptional activity with low micromolar potency, with $\mathrm{IC}_{50}$ (half-maximal inhibitory concentration) values of: $22.7 \mu \mathrm{M}$ for VPC-70067 comparable to that of the control compound 10058-F4 $(28.9 \mu \mathrm{M})$, and $8.9 \mu \mathrm{M}$ for VPC-70063 (Fig. 2A).

Effects of hit compounds on Myc-Max downstream-regulated pathways. It has been recently reported that Myc inhibition can reduce the levels of the constitutively active androgen receptor splice variant AR-V7 in androgen-deprived 22rv1 cells [20]. AR-V7 has been shown to specifically regulate the expression level of the Ubiquitin Conjugating Enzyme E2C (UBE2C) in androgen-deprived 22rv1, through the UBE2C promoter [21]. Hence, a complementary transcriptional screening assay was developed in house to monitor the expression levels of the AR-V7 isoform in 22rv1 cells by using a plasmid containing a UBE2C promoter linked to a luciferase reporter. The dose-dependent reduction of luciferase levels by the identified hits indicates a Myc-related reduction of AR-V7 level in the cells (see Table 1). The AR-V7 reduction with the hits was confirmed by Western Blot (data not shown). Compound VPC-70063 showed the highest V7 reduction levels.

2.4. Effects of hit compounds on cell viability. The effect of hit compounds on Myc-driven cell proliferation was evaluated by measuring the cell viability of $\mathrm{LNCaP}$ cells after treatment with increasing concentrations of the lead compounds. We also used Myc knockout HO15.19 cell line to exclude any off-target effect. Again, 
VPC-70063 showed the best inhibition of LNCaP cell proliferation with minimal cytotoxic at much higher concentrations as seen in the Myc knockout HO15.19 cell line (Fig. 2B).

\subsection{Mechanism of action of hit compounds.}

\subsubsection{Apoptosis.}

Myc inhibition has been shown to induce cell death by cell cycle arrest and apoptosis [58]. Cleavage of PARP-1 by caspases is considered a hallmark of apoptosis and so we measured the ability of our compounds to induce PARP cleavage after treatment. As predicted, VPC-70063 and VPC-70067 were inducing PARP cleavage suggesting that the effect of these two compounds were through apoptosis pathways (Fig. 3A).

\subsubsection{Direct Binding and disruption of protein-DNA interaction.}

To study the direct effect of our lead compounds VPC-70063 and VPC-70067 on the interaction between Myc-Max heterodimer and the DNA, we used Bio-Layer Interferometry (BLI, ForteBio). This technique is a label-free technology allowing the measurement of direct interactions between two partners, one immobilized on a sensor and the other one present in a solution. We applied this technology to study the disruption of the interaction between a biotinylated E-box oligo immobilized on a streptavidin biosensor and a purified MycMax complex in presence of our compounds. Therefore, histidine-tagged Max (residues 23-102) and GST tagged Myc (residues 368-454) were overexpressed and co-purified. The fraction containing equal amount of Myc and Max was collected and used for the binding assay (Fig. 3A). The presence of both proteins was validated by western blot using a specific antibody of each protein. Using BLI, we were able to show that Myc-Max heterodimer was prevented from interacting with the immobilized DNA in presence of both VPC70063 and VPC-70067 similarly to the control 10074-G5 (Fig. 3C). Additionally, our lead VPC-70063 showed a dose dependent inhibition of the DNA/heterodimer interaction (Fig. 3D). 


\subsubsection{The effect of inhibitors on Myc-Max interaction using mammalian 2-hybrid assay}

We studied the effect of our inhibitors on Myc-Max interaction by using a mammalian two hybrid assay. Full lengths Myc and Max were cloned in pBIND and pACT plasmids (CheckMate, Promega), respectively. Luciferase levels corresponding to Myc-Max interactions were measured and normalized to a control provided by the commercial kit to discard non-specific effect due to toxicity or direct luciferase inhibition. Our inhibitor VPC-70063 showed a dose response inhibition of the interaction between the two proteins (Fig. 3E).

2.6. In silico binding mode of VPC-70063. As described above, compound VPC-70063 was the best performer in all the cell-based and cell-free assays designed for this study. The predicted binding pose of VPC-70063 (1benzyl-3-(3,5-bis(trifluoromethyl)phenyl)thiourea), obtained using computational modeling methods, is shown in Fig. 4. The chemical structure of VPC-70063 is composed of a benzyl ring at one end, a thiourea linker and a highly hydrophobic 3,5-bis(trifluoromethyl)phenyl moiety at the other end. Within the binding pocket of the Myc-Max DBD domain, VPC-70063 is predicted to form 2 hydrogen bonds between the 2 thiourea amine hydrogens and the backbone carbonyl of Arg215 (Fig. 4B, magenta dashed lines), as well as a large number of strong hydrophobic interactions (Fig. 4B, green dashed lines) formed by the 3,5bis(trifluoromethyl)phenyl moiety with the hydrophobic core of the pocket, including aliphatic and aromatic side-chains of Leu917, Phe921, and Lys939 of Myc, and Ile218, Phe222, and Arg215 of Max, and those formed by the benzyl ring with aliphatic side chains of Arg215 and Arg212 of Max. Noteworthy, as shown in Fig. 4A, the 3,5-bis(trifluoromethyl)phenyl group of VPC-70063 is matching the hydrophobic features of the constructed pharmacophore, it is deeply buried in the hydrophobic core of the Myc-Max DBD pocket being stabilized via hydrophobic interactions. Furthermore, in the binding pose, the benzyl ring of VPC-70063 is predicted to overlap significantly with the DNA backbone. Therefore, it was expected that VPC-70063, in as much as other hits having similar interactions, would overcome the binding of DNA to the Myc-Max DBD site. It is not surprisingly then that VPC-70063 blocks the binding of Myc-Max to DNA as determined by BLI 
measurements. Further experiments may be though required to unequivocally prove the binding mode and direct disruption of protein-DNA interactions with our current hits and future derivatives.

\section{Discussion and future perspectives. Hit-to-lead optimization.}

Findings reported in this study prompted us to leverage the full power of our in silico drug discovery platform that proved successful in targeting unconventional sites on protein surfaces and in yielding promising preclinical drug candidates for previously uncharted targets [59-67]. Consequently, we have initiated ligand-based similarity searches followed by molecular docking and consensus scoring computations to identify analogs of the initial hit compounds (Fig. 5A). Briefly, three-dimensional similarity searches are conducted utilizing the ROCS program from OpenEye [68, 69] against a large ensemble of conformers consisting of at most 200 conformers for each of the approximately 9 million entries of the drug-like purchasable chemical space of the ZINC15 database [70]. Conformers are generated using Omega2 of OpenEye [71]. Current hits are used as query molecules. ROCS is a fast shape-based superposition method, which uses a combination of global three-dimensional shape overlay and color-based chemical complementarity in terms of hydrogen-bond donors, hydrogen-bond acceptors, hydrophobes, anions, cations and rings, to compare the query to a large collection of molecules and rank the matching hitlist according to the TanimotoCombo score, a rigorous measure of shape and color overlap. Molecular docking, using 3 docking programs differing in their underlying scoring functions and sampling algorithms: Glide [55, 56], ICM [72] and Hybrid [73, 74], is employed to position analogs into the Myc-Max DBD. Consensus voting and filtering using various thresholds is subsequently performed. The consensus is built based on top-ranking docking scores (the more negative the stronger the binding affinity; e.g. Glide score $\leq-5.5 \mathrm{kcal} / \mathrm{mol}$ ) and calculation, using MOE scripts [75, 76], of two indicators: root mean square deviation (RMSD), an atombased metric reflecting the deviation in atomic coordinates between poses obtained from the three docking programs, and predicted $\mathrm{pKi}$, a good indicator of potency. The filtering thresholds used are: RMSD $\leq 3 \AA$ (an 
RMSD of 0 indicates perfect superposition; the higher the RMSD the greater the deviation), and $\mathrm{pKi} \geq 5$ (the larger more potent theoretically). All high-confidence analogs are subsequently subjected to full experimental profiling. Quantitative (QSAR) models based on our in-house developed 3D and 4D inductive descriptors [77, 78] are currently customized for Myc-Max target to serve as an additional scoring function for accurate activity prediction of analogs and future derivative series.

In the longer term and as per our usual practices [79], the target affinity and drug-like profile of the most promising analogs will be optimized based on observed structure activity relationship (SAR) in iterative rounds of in silico modeling, medicinal chemistry and biological validation, until a lead is found (Fig. 5B). In this process, for more elaborate and accurate scoring, computationally-demanding classical molecular dynamics (MD) and free energy perturbation MD simulations [80-85] will be executed on GPU-accelerated clusters. Moreover, the drug-like profile of promising derivatives will be improved by eliminating toxic moieties and metabolically labile centers as predicted by SimulationsPlus ADMET Predictor software [86]. This approach will allow us to achieve highly potent binding while maintaining other ligand properties required for safety and biological efficacy.

\section{Conclusions}

In the absence of clinically approved anti-Myc drugs, targeting the Myc-Max complex represents a critical step towards creating new therapeutics for lethal CRPC and NEPC. In this study, we identified a possible druggable site on the DNA-binding domain (DBD) of the structurally ordered Myc-Max complex and employed our ever-growing computer-aided rational drug discovery technology to identify small molecules binders that inhibit Myc-Max functionality. A large-scale virtual screening protocol was utilized to select a set of top-ranked compounds that were subsequently characterized experimentally. A number of compounds were identified that inhibit Myc-Max activity with low micromolar potency and no apparent cytotoxicity. Among these, on one hand, compound VPC-70067 highly similar in structure, potency and mechanism of action to 
10058-F4, identified using an approach independent from the one used in the literature, serves as proof-ofconcept that our in silico drug discovery strategy works as expected. On the other hand, compound VPC70063 of a chemically different scaffold is the best performer in a panel of cell-based and in vitro assays as it inhibits Myc-Max transcriptional activity $\left(\mathrm{IC}_{50}=8.9 \mu \mathrm{M}\right)$, inhibits Myc-Max downstream functions reducing the levels of the AR-V7 splice variant in CRPC cells, reduces cell growth in various PCa cell lines, but has no effect on the viability of the Myc knockout HO15.19 cells, therefore is Myc-Max specific and generically non-toxic. VPC-70063 induces apoptosis confirming that the observed viability reduction is not due to the toxicity of the compound but is instead a mechanistic effect. Moreover, VPC-70063 blocks Myc-Max-DNA interactions. VPC-70063 is the forerunner currently prioritized for our ongoing hit-to-lead optimization efforts based on observed structure activity relationships (SAR). As before, our integrative approach to drug discovery proved successful insofar in discovering novel Myc-Max inhibitors as promising far-reaching therapeutics for lethal prostate cancer.

\section{Materials and Methods}

Virtual screening of potential Myc-Max DBD inhibitors.

The published $1.9 \AA$ crystal structure of c-Myc-Max heterodimer bound to its DNA-recognition sequence (PDB ID:1NKP [34], chains A, B; waters and DNA excluded) was subjected to the Site Finder algorithm implemented in MOE [51]. Site Finder is a geometric method which uses alpha spheres (virtual atoms) to probe a protein surface for suitable small molecule binding pockets. Briefly, Site Finder first identifies regions of tight atomic packing, filters out highly solvent exposed sites, calculates alpha spheres on sites and classifies them as either hydrophobic or hydrophilic depending on whether the virtual atom is in a good hydrogen bonding spot in the receptor, and then produces a collection of sites based on pruning (alpha spheres corresponding to inaccessible regions or exposed to solvent are eliminated) and clustering (by number and chemical type) of alpha spheres. The sites are then rank according to their Propensity for Ligand Binding 
(PLB) score. The top PDB-ranked pocket was used for subsequent in silico screening. Virtual screening of the ZINC12 database [53, 54] was performed using structure-based methods including molecular docking algorithms and pharmacophore screening. The Glide program [55, 56], part of Maestro 9.3 suite, Schrödinger LLC [57], was used as the starting point to perform rigid docking of 4.7 million drug-like chemicals. Following Maestro's standard protein preparation protocol [87, 88], applied to the Myc-Max X-ray structure, a docking grid was defined as a $20 \AA$ box centered on the residues of predicted Myc-Max DBD binding site for Glide sampling and scoring of screening compounds. Prior to docking, each chemical was washed and energy-minimized under the MMFF94x force field and Born solvation as per ligand preparation protocol implemented in MOE [51]. Docking was conducted using Glide standard precision mode with all other settings set to default. The generated docking poses were ranked by the Glide score, an interaction energy score that includes hydrogen bonding and hydrophobic interactions contributions. Potentially weak binders (Glide score $>-5.5 \mathrm{kcal} / \mathrm{mol}$ ) were discarded. The remaining top-ranked 12503 remaining compounds were further filtered by structure-based pharmacophore screening using MOE's tools [51]. A pharmacophore model of two essential hydrophobic features (1.5 A diameter each) of the binding site (formed primarily by Leu917, Ile218, Phe921 and Phe222) was built and used to search for matching hits in the database of top ranked Glide poses. 1019 pharmacophore-matching hits were then selected for manual inspection using the 3D visual environment in MOE. 69 compounds having a good balance of Glide docking score and ligand efficiency and making favorable interactions with the surrounding side chains in the pocket were purchased for subsequent experimental testing.

\section{Cell culture and reagents}

LNCaP and PC3 cells were purchased from the ATCC and grown in RPMI 1640 supplemented with 10\% fetal bovine serum (FBS). HO15.19 cells were a generous gift from John Sidivy at Brown University and 
were cultured in Dulbecco's modified Eagle's medium DMEM (ATCC 30-2002) supplemented with 10\% FBS. 10058-F4 and 10074-G5 were obtained from Sigma. The UBE2C reporter plasmid was purchased from GeneCopoeia (product ID \#HPRM16429). The Biolux Gaussia luciferase assay kit was purchased from New England Biolab (\#E3300L). PrestoBlue cell viability reagent was purchased from Invitrogen \#A-13262.

\section{Transfection and Reporter Assays}

Cell transfection was performed using TransIT-2020 transfection reagents according to the manufacturer's instructions. LNCaP cells were plated at 10000 cells per well and treated for 1 day with the indicated concentration of compound. Myc reporter activity was measured using the Cignal Myc Reporter Assay Kit from Qiagen (\#336841) according to the manufacturer's instructions. For the UBE2C reporter assay, 22rv1 cells were plated at 10000 cells per well in 96-well plates in RPMI media supplemented with 5\% charcoalstripped serum (CSS) and treated for 1 day with $1 \mathrm{uM}, 10 \mathrm{uM}$ and $25 \mathrm{uM}$ of compound.

\section{Cell viability assays}

LNCaP were plated at 5000 cells per well in RPMI 1640 containing 5\% CSS in a 96-well plate, treated with test compounds $(0-25 \mu \mathrm{M})$ for 96 hours. Cell density was measured using the PrestoBlue assay according to the manufacturer's protocol. The percentage of cell survival was normalized to the cell density of control wells treated by vehicle. Viability of Myc-negative HO15.19 cells was done similarly but in DMEM supplemented with $5 \%$ CSS.

c-Myc-Max purification 
Histidine tagged Max (residues 23-102) and GST tagged Myc (residues 368-454) were overexpressed in $E$. coli BL21-DE3 cells. Cells were co-lyzed in lysis buffer $(20 \mathrm{mM}$ Tris $\mathrm{pH}$ 8, $500 \mathrm{mM} \mathrm{NaCl}, 5 \%$ glycerol, 10 $\mathrm{mM}$ imidazole, $8 \mathrm{mM}$ BME, $2.1 \mathrm{mM}$ PMSF). After sonication and centrifugation, the complex was first purified by using a Ni-NTA affinity resin. After overnight dialysis to remove the imidazole, the protein sample was applied to a size exclusion chromatography equilibrated with $(20 \mathrm{mM}$ Tris $\mathrm{pH} 8,150 \mathrm{mM} \mathrm{NaCl}$, $5 \%$ glycerol, $0.2 \mathrm{mM}$ TCEP). Fractions containing equal amount of Myc and Max on SDS PAGE were collected and used for the binding assay. The presence of both proteins was validated by western blot using a specific antibody of each protein (Max (h2) Sc-8011 and c-Myc (9E10) Sc-40, Santa Cruz Biotechnology).

\section{Biolayer Interferometry assay}

The direct interaction between biotinylated E-box oligo (TGAAGCAGACCACGTGGTCGTCTTCA) immobilized on a streptavidin biosensor and a purified Myc-Max complex $(0.05 \mathrm{mg} / \mathrm{ml})$ was quantified by BLI using OctetRED (ForteBio). The DNA was first bound to the super-streptavidin sensors over $1000 \mathrm{sec}$ at $25^{\circ} \mathrm{C}$. The sensors were next moved into wells containing the reaction buffer $(20 \mathrm{mM}$ Tris $\mathrm{pH} 8,150 \mathrm{mM}$ $\mathrm{NaCl}, 5 \%$ glycerol, $0.2 \mathrm{mM}$ TCEP, $5 \%$ dimethylsulfoxide) for baseline and next into the Myc-Max complex alone or in presence of the tested inhibitors.

\section{Western Blotting}

After 48 hours of treatment with Myc compounds, LNCaP cells were lysed and protein sample preparation and Western blotting were performed as previously described [89]. Blots were incubated with primary antibodies against c-Myc, PARP (Sigma 084M4766V), PARP cleaved-Asp214 (Sigma SAB4500487) and $\beta$ Actin (Sigma A2066) overnight at $4{ }^{\circ} \mathrm{C}$, followed by appropriate peroxidase-conjugated secondary antibodies. 
$\beta$-actin served as an internal control. Visualization of the immunocomplexes was done by an enhanced chemiluminescence detection system (Millipore) followed by exposure to X-ray films.

\section{Mammalian two-hybrid assay}

Full lengths Myc and Max were cloned in pBIND and pACT plasmids (CheckMate, Promega), respectively. PC3 cells in RPMI 1640 supplemented with 5\% FBS were seeded in 96-well plates at 5,000 cells/well. After 24 hours, cells were transfected with $15 \mathrm{ng}$ of pACT-Max, $19.5 \mathrm{ng}$ of pBIND-Myc, and 13.6 ng of the reporter plasmid PG5-luciferase. After 24 hours, cells were treated with various concentrations of the tested inhibitors. Cells were lysed the next day, and the luminescence signal was measured after adding 50 $\mu \mathrm{L}$ of luciferase assay reagent (Promega). Each measurement was done in 4 replicates with biological replicates of 3. Luciferase levels corresponding to Myc-Max interactions were measured and normalized to a control provided by the commercial kit to discard non-specific effect due to toxicity or direct luciferase inhibition.

\section{Acknowledgements}

This research was supported by the Government of Canada with the Centre of Excellence for Commercialization and Research (CECR) program. L.A. Carabet is supported by Prostate Cancer Canada NextGen 2017 Philip Feldberg graduate studentship award.

\section{Conflicts of interest}

The authors declare no conflicts of interest. 


\section{References}

[1] C.V. Dang, MYC on the path to cancer, Cell, 149 (2012) 22-35.

[2] C.V. Dang, MYC, metabolism, cell growth, and tumorigenesis, Cold Spring Harbor perspectives in medicine, 3 (2013).

[3] C.V. Dang, L.M. Resar, E. Emison, S. Kim, Q. Li, J.E. Prescott, D. Wonsey, K. Zeller, Function of the c-Myc oncogenic transcription factor, Experimental cell research, 253 (1999) 63-77.

[4] R. Ponzielli, S. Katz, D. Barsyte-Lovejoy, L.Z. Penn, Cancer therapeutics: targeting the dark side of Myc, European journal of cancer, 41 (2005) 2485-2501.

[5] M. Huang, W.A. Weiss, Neuroblastoma and MYCN, Cold Spring Harbor perspectives in medicine, 3 (2013) a014415.

[6] Z.E. Stine, Z.E. Walton, B.J. Altman, A.L. Hsieh, C.V. Dang, MYC, Metabolism, and Cancer, Cancer discovery, 5 (2015) $1024-1039$.

[7] S.B. McMahon, MYC and the control of apoptosis, Cold Spring Harbor perspectives in medicine, 4 (2014) a014407.

[8] M. Gabay, Y. Li, D.W. Felsher, MYC activation is a hallmark of cancer initiation and maintenance, Cold Spring Harbor perspectives in medicine, 4 (2014).

[9] D. Horiuchi, B. Anderton, A. Goga, Taking on challenging targets: making MYC druggable, American Society of Clinical Oncology educational book. American Society of Clinical Oncology. Meeting, (2014) e497-502.

[10] C.M. Koh, C.J. Bieberich, C.V. Dang, W.G. Nelson, S. Yegnasubramanian, A.M. De Marzo, MYC and Prostate Cancer, Genes \& cancer, 1 (2010) 617-628.

[11] P.C. Boutros, M. Fraser, N.J. Harding, R. de Borja, D. Trudel, E. Lalonde, A. Meng, P.H. Hennings-Yeomans, A. McPherson, V.Y. Sabelnykova, A. Zia, N.S. Fox, J. Livingstone, Y.J. Shiah, J. Wang, T.A. Beck, C.L. Have, T. Chong, M. Sam, J. Johns, L. Timms, N. Buchner, A. Wong, J.D. Watson, T.T. Simmons, C. P'ng, G. Zafarana, F. Nguyen, X. Luo, K.C. Chu, S.D. Prokopec, J. Sykes, A. Dal Pra, A. Berlin, A. Brown, M.A. Chan-Seng-Yue, F. Yousif, R.E. Denroche, L.C. Chong, G.M. Chen, E. Jung, C. Fung, M.H. Starmans, H. Chen, S.K. Govind, J. Hawley, A. D'Costa, M. Pintilie, D. Waggott, F. Hach, P. Lambin, L.B. Muthuswamy, C. Cooper, R. Eeles, D. Neal, B. Tetu, C. Sahinalp, L.D. Stein, N. Fleshner, S.P. Shah, C.C. Collins, T.J. Hudson, J.D. McPherson, T. van der Kwast, R.G. Bristow, Spatial genomic heterogeneity within localized, multifocal prostate cancer, Nature genetics, 47 (2015) 736-745.

[12] A.W. Wyatt, M.E. Gleave, Targeting the adaptive molecular landscape of castration-resistant prostate cancer, EMBO molecular medicine, 7 (2015) 878-894.

[13] H. Beltran, S. Tomlins, A. Aparicio, V. Arora, D. Rickman, G. Ayala, J. Huang, L. True, M.E. Gleave, H. Soule, C. Logothetis, M.A. Rubin, Aggressive variants of castration-resistant prostate cancer, Clinical cancer research : an official journal of the American Association for Cancer Research, 20 (2014) 2846-2850.

[14] H. Beltran, D. Prandi, J.M. Mosquera, M. Benelli, L. Puca, J. Cyrta, C. Marotz, E. Giannopoulou, B.V. Chakravarthi, S. Varambally, S.A. Tomlins, D.M. Nanus, S.T. Tagawa, E.M. Van Allen, O. Elemento, A. Sboner, L.A. Garraway, M.A. Rubin, F. Demichelis, 
Divergent clonal evolution of castration-resistant neuroendocrine prostate cancer, Nature medicine, 22 (2016) 298-305.

[15] H. Beltran, D.S. Rickman, K. Park, S.S. Chae, A. Sboner, T.Y. MacDonald, Y. Wang, K.L. Sheikh, S. Terry, S.T. Tagawa, R. Dhir, J.B. Nelson, A. de la Taille, Y. Allory, M.B. Gerstein, S. Perner, K.J. Pienta, A.M. Chinnaiyan, Y. Wang, C.C. Collins, M.E. Gleave, F. Demichelis, D.M. Nanus, M.A. Rubin, Molecular characterization of neuroendocrine prostate cancer and identification of new drug targets, Cancer discovery, 1 (2011) 487-495.

[16] D. Bernard, A. Pourtier-Manzanedo, J. Gil, D.H. Beach, Myc confers androgen-independent prostate cancer cell growth, The Journal of clinical investigation, 112 (2003) 1724-1731.

[17] J.H. Kim, S.M. Dhanasekaran, R. Mehra, S.A. Tomlins, W. Gu, J. Yu, C. Kumar-Sinha, X. Cao, A. Dash, L. Wang, D. Ghosh, K. Shedden, J.E. Montie, M.A. Rubin, K.J. Pienta, R.B. Shah, A.M. Chinnaiyan, Integrative analysis of genomic aberrations associated with prostate cancer progression, Cancer research, 67 (2007) 8229-8239.

[18] S.J. Barfeld, A. Urbanucci, H.M. Itkonen, L. Fazli, J.L. Hicks, B. Thiede, P.S. Rennie, S. Yegnasubramanian, A.M. DeMarzo, I.G. Mills, c-Myc Antagonises the Transcriptional Activity of the Androgen Receptor in Prostate Cancer Affecting Key Gene Networks, EBioMedicine, 18 (2017) 83-93.

[19] A.V. Lapuk, S.V. Volik, Y. Wang, C.C. Collins, The role of mRNA splicing in prostate cancer, Asian journal of andrology, 16 (2014) 515-521.

[20] N. Nadiminty, R. Tummala, C. Liu, W. Lou, C.P. Evans, A.C. Gao, NF-kappaB2/p52:c-Myc:hnRNPA1 Pathway Regulates Expression of Androgen Receptor Splice Variants and Enzalutamide Sensitivity in Prostate Cancer, Molecular cancer therapeutics, 14 (2015) 1884-1895.

[21] R. Hu, C. Lu, E.A. Mostaghel, S. Yegnasubramanian, M. Gurel, C. Tannahill, J. Edwards, W.B. Isaacs, P.S. Nelson, E. Bluemn, S.R. Plymate, J. Luo, Distinct transcriptional programs mediated by the ligand-dependent full-length androgen receptor and its splice variants in castration-resistant prostate cancer, Cancer research, 72 (2012) 3457-3462.

[22] S. Akamatsu, T. Inoue, O. Ogawa, M.E. Gleave, Clinical and molecular features of treatment-related neuroendocrine prostate cancer, International journal of urology : official journal of the Japanese Urological Association, 25 (2018) 345-351.

[23] E.M. Blackwood, R.N. Eisenman, Max: a helix-loop-helix zipper protein that forms a sequence-specific DNA-binding complex with Myc, Science, 251 (1991) 1211-1217.

[24] G.J. Kato, W.M. Lee, L.L. Chen, C.V. Dang, Max: functional domains and interaction with c-Myc, Genes \& development, 6 (1992) 81-92.

[25] W.D. Thomas, A. Raif, L. Hansford, G. Marshall, N-myc transcription molecule and oncoprotein, The international journal of biochemistry \& cell biology, 36 (2004) 771-775.

[26] M. Conacci-Sorrell, L. McFerrin, R.N. Eisenman, An overview of MYC and its interactome, Cold Spring Harbor perspectives in medicine, 4 (2014) a014357. 
[27] J. Michel, R. Cuchillo, The impact of small molecule binding on the energy landscape of the intrinsically disordered protein C-myc, PloS one, 7 (2012) e41070.

[28] F. Jin, C. Yu, L. Lai, Z. Liu, Ligand clouds around protein clouds: a scenario of ligand binding with intrinsically disordered proteins, PLoS computational biology, 9 (2013) e1003249.

[29] C. Yu, X. Niu, F. Jin, Z. Liu, C. Jin, L. Lai, Structure-based Inhibitor Design for the Intrinsically Disordered Protein c-Myc, Scientific reports, 6 (2016) 22298.

[30] B. Luscher, L.G. Larsson, The basic region/helix-loop-helix/leucine zipper domain of Myc proto-oncoproteins: function and regulation, Oncogene, 18 (1999) 2955-2966.

[31] A. Sabo, B. Amati, Genome recognition by MYC, Cold Spring Harbor perspectives in medicine, 4 (2014).

[32] P.B. Rahl, R.A. Young, MYC and transcription elongation, Cold Spring Harbor perspectives in medicine, 4 (2014) a020990.

[33] A.R. Ferre-D'Amare, G.C. Prendergast, E.B. Ziff, S.K. Burley, Recognition by Max of its cognate DNA through a dimeric b/HLH/Z domain, Nature, 363 (1993) 38-45.

[34] S.K. Nair, S.K. Burley, X-ray structures of Myc-Max and Mad-Max recognizing DNA. Molecular bases of regulation by protooncogenic transcription factors, Cell, 112 (2003) 193-205.

[35] L. Soucek, J. Whitfield, C.P. Martins, A.J. Finch, D.J. Murphy, N.M. Sodir, A.N. Karnezis, L.B. Swigart, S. Nasi, G.I. Evan, Modelling Myc inhibition as a cancer therapy, Nature, 455 (2008) 679-683.

[36] L. Soucek, J.R. Whitfield, N.M. Sodir, D. Masso-Valles, E. Serrano, A.N. Karnezis, L.B. Swigart, G.I. Evan, Inhibition of Myc family proteins eradicates KRas-driven lung cancer in mice, Genes \& development, 27 (2013) 504-513.

[37] X. Yin, C. Giap, J.S. Lazo, E.V. Prochownik, Low molecular weight inhibitors of Myc-Max interaction and function, Oncogene, 22 (2003) 6151-6159.

[38] J.L. Yap, H. Wang, A. Hu, J. Chauhan, K.Y. Jung, R.B. Gharavi, E.V. Prochownik, S. Fletcher, Pharmacophore identification of cMyc inhibitor 10074-G5, Bioorganic \& medicinal chemistry letters, 23 (2013) 370-374.

[39] D. Stellas, M. Szabolcs, S. Koul, Z. Li, A. Polyzos, C. Anagnostopoulos, Z. Cournia, C. Tamvakopoulos, A. Klinakis, A. Efstratiadis, Therapeutic effects of an anti-Myc drug on mouse pancreatic cancer, Journal of the National Cancer Institute, 106 (2014).

[40] J.R. Hart, A.L. Garner, J. Yu, Y. Ito, M. Sun, L. Ueno, J.K. Rhee, M.M. Baksh, E. Stefan, M. Hartl, K. Bister, P.K. Vogt, K.D. Janda, Inhibitor of MYC identified in a Krohnke pyridine library, Proceedings of the National Academy of Sciences of the United States of America, 111 (2014) 12556-12561.

[41] J.R. Whitfield, M.E. Beaulieu, L. Soucek, Strategies to Inhibit Myc and Their Clinical Applicability, Frontiers in cell and developmental biology, 5 (2017) 10.

[42] C.M. Koh, A. Sabo, E. Guccione, Targeting MYC in cancer therapy: RNA processing offers new opportunities, BioEssays : news and reviews in molecular, cellular and developmental biology, 38 (2016) 266-275. 
[43] M.R. McKeown, J.E. Bradner, Therapeutic strategies to inhibit MYC, Cold Spring Harbor perspectives in medicine, 4 (2014).

[44] D.S. Rickman, J.H. Schulte, M. Eilers, The Expanding World of N-MYC-Driven Tumors, Cancer discovery, 8 (2018) $150-163$.

[45] A.V. Follis, D.I. Hammoudeh, H. Wang, E.V. Prochownik, S.J. Metallo, Structural rationale for the coupled binding and unfolding of the c-Myc oncoprotein by small molecules, Chemistry \& biology, 15 (2008) 1149-1155.

[46] D.I. Hammoudeh, A.V. Follis, E.V. Prochownik, S.J. Metallo, Multiple independent binding sites for small-molecule inhibitors on the oncoprotein c-Myc, Journal of the American Chemical Society, 131 (2009) 7390-7401.

[47] H. Wang, D.I. Hammoudeh, A.V. Follis, B.E. Reese, J.S. Lazo, S.J. Metallo, E.V. Prochownik, Improved low molecular weight Myc-Max inhibitors, Molecular cancer therapeutics, 6 (2007) 2399-2408.

[48] H. Wang, J. Chauhan, A. Hu, K. Pendleton, J.L. Yap, P.E. Sabato, J.W. Jones, M. Perri, J. Yu, E. Cione, M.A. Kane, S. Fletcher, E.V. Prochownik, Disruption of Myc-Max heterodimerization with improved cell-penetrating analogs of the small molecule 10074-G5, Oncotarget, 4 (2013) 936-947.

[49] J. Guo, R.A. Parise, E. Joseph, M.J. Egorin, J.S. Lazo, E.V. Prochownik, J.L. Eiseman, Efficacy, pharmacokinetics, tisssue distribution, and metabolism of the Myc-Max disruptor, 10058-F4 [Z,E]-5-[4-ethylbenzylidine]-2-thioxothiazolidin-4-one, in mice, Cancer chemotherapy and pharmacology, 63 (2009) 615-625.

[50] D.M. Clausen, J. Guo, R.A. Parise, J.H. Beumer, M.J. Egorin, J.S. Lazo, E.V. Prochownik, J.L. Eiseman, In vitro cytotoxicity and in vivo efficacy, pharmacokinetics, and metabolism of 10074-G5, a novel small-molecule inhibitor of c-Myc/Max dimerization, The Journal of pharmacology and experimental therapeutics, 335 (2010) 715-727.

[51] Molecular Operating Environment (MOE), 2013.08; Chemical Computing Group ULC, 1010 Sherbooke St. West, Suite \#910, Montreal, QC, Canada, H3A 2R7, 2018.

[52] L.A. Jung, A. Gebhardt, W. Koelmel, C.P. Ade, S. Walz, J. Kuper, B. von Eyss, S. Letschert, C. Redel, L. d'Artista, A. Biankin, L. Zender, M. Sauer, E. Wolf, G. Evan, C. Kisker, M. Eilers, OmoMYC blunts promoter invasion by oncogenic MYC to inhibit gene expression characteristic of MYC-dependent tumors, Oncogene, 36 (2017) 1911-1924.

[53] J.J. Irwin, B.K. Shoichet, ZINC--a free database of commercially available compounds for virtual screening, Journal of chemical information and modeling, 45 (2005) 177-182.

[54] J.J. Irwin, T. Sterling, M.M. Mysinger, E.S. Bolstad, R.G. Coleman, ZINC: a free tool to discover chemistry for biology, Journal of chemical information and modeling, 52 (2012) 1757-1768.

[55] R.A. Friesner, J.L. Banks, R.B. Murphy, T.A. Halgren, J.J. Klicic, D.T. Mainz, M.P. Repasky, E.H. Knoll, M. Shelley, J.K. Perry, D.E. Shaw, P. Francis, P.S. Shenkin, Glide: a new approach for rapid, accurate docking and scoring. 1. Method and assessment of docking accuracy, Journal of medicinal chemistry, 47 (2004) 1739-1749.

[56] T.A. Halgren, R.B. Murphy, R.A. Friesner, H.S. Beard, L.L. Frye, W.T. Pollard, J.L. Banks, Glide: a new approach for rapid, accurate docking and scoring. 2. Enrichment factors in database screening, Journal of medicinal chemistry, 47 (2004) 1750-1759. 
[57] Schrödinger Release 2018-1: Maestro, Schrödinger, LLC, New York, NY, 2018.

[58] M.J. Huang, Y.C. Cheng, C.R. Liu, S. Lin, H.E. Liu, A small-molecule c-Myc inhibitor, 10058-F4, induces cell-cycle arrest, apoptosis, and myeloid differentiation of human acute myeloid leukemia, Experimental hematology, 34 (2006) 1480-1489.

[59] N. Lallous, K. Dalal, A. Cherkasov, P.S. Rennie, Targeting alternative sites on the androgen receptor to treat castration-resistant prostate cancer, International journal of molecular sciences, 14 (2013) 12496-12519.

[60] P. Axerio-Cilies, N.A. Lack, M.R. Nayana, K.H. Chan, A. Yeung, E. Leblanc, E.S. Guns, P.S. Rennie, A. Cherkasov, Inhibitors of androgen receptor activation function-2 (AF2) site identified through virtual screening, Journal of medicinal chemistry, 54 (2011) 6197 6205.

[61] N.A. Lack, P. Axerio-Cilies, P. Tavassoli, F.Q. Han, K.H. Chan, C. Feau, E. LeBlanc, E.T. Guns, R.K. Guy, P.S. Rennie, A. Cherkasov, Targeting the binding function 3 (BF3) site of the human androgen receptor through virtual screening, Journal of medicinal chemistry, 54 (2011) 8563-8573.

[62] R.S. Munuganti, E. Leblanc, P. Axerio-Cilies, C. Labriere, K. Frewin, K. Singh, M.D. Hassona, N.A. Lack, H. Li, F. Ban, E. Tomlinson Guns, R. Young, P.S. Rennie, A. Cherkasov, Targeting the binding function 3 (BF3) site of the androgen receptor through virtual screening. 2. development of 2-((2-phenoxyethyl) thio)-1H-benzimidazole derivatives, Journal of medicinal chemistry, 56 (2013) 1136-1148.

[63] R.S. Munuganti, M.D. Hassona, E. Leblanc, K. Frewin, K. Singh, D. Ma, F. Ban, M. Hsing, H. Adomat, N. Lallous, C. Andre, J.P. Jonadass, A. Zoubeidi, R.N. Young, E.T. Guns, P.S. Rennie, A. Cherkasov, Identification of a potent antiandrogen that targets the BF3 site of the androgen receptor and inhibits enzalutamide-resistant prostate cancer, Chemistry \& biology, 21 (2014) 1476-1485.

[64] F. Ban, E. Leblanc, H. Li, R.S. Munuganti, K. Frewin, P.S. Rennie, A. Cherkasov, Discovery of 1H-indole-2-carboxamides as novel inhibitors of the androgen receptor binding function 3 (BF3), Journal of medicinal chemistry, 57 (2014) 6867-6872.

[65] H. Li, M.D. Hassona, N.A. Lack, P. Axerio-Cilies, E. Leblanc, P. Tavassoli, N. Kanaan, K. Frewin, K. Singh, H. Adomat, K.J. Bohm, H. Prinz, E.T. Guns, P.S. Rennie, A. Cherkasov, Characterization of a new class of androgen receptor antagonists with potential therapeutic application in advanced prostate cancer, Molecular cancer therapeutics, 12 (2013) 2425-2435.

[66] H. Li, F. Ban, K. Dalal, E. Leblanc, K. Frewin, D. Ma, H. Adomat, P.S. Rennie, A. Cherkasov, Discovery of small-molecule inhibitors selectively targeting the DNA-binding domain of the human androgen receptor, Journal of medicinal chemistry, 57 (2014) 6458-6467.

[67] K. Dalal, M. Roshan-Moniri, A. Sharma, H. Li, F. Ban, M.D. Hassona, M. Hsing, K. Singh, E. LeBlanc, S. Dehm, E.S. Tomlinson Guns, A. Cherkasov, P.S. Rennie, Selectively targeting the DNA-binding domain of the androgen receptor as a prospective therapy for prostate cancer, The Journal of biological chemistry, 289 (2014) 26417-26429.

[68] P.C. Hawkins, A.G. Skillman, A. Nicholls, Comparison of shape-matching and docking as virtual screening tools, Journal of medicinal chemistry, 50 (2007) 74-82. 
[69] OpenEye Scientific Software, Santa Fe, NM. http://www.eyesopen.com (last accessed May, 2018).

[70] T. Sterling, J.J. Irwin, ZINC 15--Ligand Discovery for Everyone, Journal of chemical information and modeling, 55 (2015) $2324-$ 2337.

[71] P.C. Hawkins, A.G. Skillman, G.L. Warren, B.A. Ellingson, M.T. Stahl, Conformer generation with OMEGA: algorithm and validation using high quality structures from the Protein Databank and Cambridge Structural Database, Journal of chemical information and modeling, 50 (2010) 572-584.

[72] M.A. Neves, M. Totrov, R. Abagyan, Docking and scoring with ICM: the benchmarking results and strategies for improvement, Journal of computer-aided molecular design, 26 (2012) 675-686.

[73] M. McGann, FRED pose prediction and virtual screening accuracy, Journal of chemical information and modeling, 51 (2011) 578596.

[74] M. McGann, FRED and HYBRID docking performance on standardized datasets, Journal of computer-aided molecular design, 26 (2012) 897-906.

[75] mol_rmsd Calculate RMSD's for docking results, Scientific Vector Language (SVL) source code provided by Chemical Computing Group ULC, 1010 Sherbooke St. West, Suite \#910, Montreal, QC, Canada, H3A 2R7, 2018.

[76] scoring Analysis tool for non-bonded intermolecular interactions: H-bonds, transition metal, water bridges, hydrophobic, Scientific Vector Language (SVL) source code provided by Chemical Computing Group ULC, 1010 Sherbooke St. West, Suite \#910, Montreal, QC, Canada, H3A 2R7, 2018.

[77] A. Cherkasov, E.N. Muratov, D. Fourches, A. Varnek, Baskin, II, M. Cronin, J. Dearden, P. Gramatica, Y.C. Martin, R. Todeschini, V. Consonni, V.E. Kuz'min, R. Cramer, R. Benigni, C. Yang, J. Rathman, L. Terfloth, J. Gasteiger, A. Richard, A. Tropsha, QSAR modeling: where have you been? Where are you going to?, Journal of medicinal chemistry, 57 (2014) 4977-5010.

[78] N. Paul, L.A. Carabet, N. Lallous, T. Yamazaki, M.E. Gleave, P.S. Rennie, A. Cherkasov, Cheminformatics Modeling of Adverse Drug Responses by Clinically Relevant Mutants of Human Androgen Receptor, Journal of chemical information and modeling, 56 (2016) $2507-2516$.

[79] F. Ban, K. Dalal, H. Li, E. LeBlanc, P.S. Rennie, A. Cherkasov, Best Practices of Computer-Aided Drug Discovery: Lessons Learned from the Development of a Preclinical Candidate for Prostate Cancer with a New Mechanism of Action, Journal of chemical information and modeling, 57 (2017) 1018-1028.

[80] Schrödinger Release 2018-1: FEP+, Schrödinger, New York, NY, 2018.

[81] R. Abel, L. Wang, E.D. Harder, B.J. Berne, R.A. Friesner, Advancing Drug Discovery through Enhanced Free Energy Calculations, Accounts of chemical research, 50 (2017) 1625-1632.

[82] B. Kuhn, M. Tichy, L. Wang, S. Robinson, R.E. Martin, A. Kuglstatter, J. Benz, M. Giroud, T. Schirmeister, R. Abel, F. Diederich, J. Hert, Prospective Evaluation of Free Energy Calculations for the Prioritization of Cathepsin L Inhibitors, Journal of medicinal 
chemistry, 60 (2017) 2485-2497.

[83] L. Wang, Y. Deng, Y. Wu, B. Kim, D.N. LeBard, D. Wandschneider, M. Beachy, R.A. Friesner, R. Abel, Accurate Modeling of Scaffold Hopping Transformations in Drug Discovery, Journal of chemical theory and computation, 13 (2017) 42-54.

[84] E. Harder, W. Damm, J. Maple, C. Wu, M. Reboul, J.Y. Xiang, L. Wang, D. Lupyan, M.K. Dahlgren, J.L. Knight, J.W. Kaus, D.S. Cerutti, G. Krilov, W.L. Jorgensen, R. Abel, R.A. Friesner, OPLS3: A Force Field Providing Broad Coverage of Drug-like Small Molecules and Proteins, Journal of chemical theory and computation, 12 (2016) 281-296.

[85] L. Wang, Y. Wu, Y. Deng, B. Kim, L. Pierce, G. Krilov, D. Lupyan, S. Robinson, M.K. Dahlgren, J. Greenwood, D.L. Romero, C. Masse, J.L. Knight, T. Steinbrecher, T. Beuming, W. Damm, E. Harder, W. Sherman, M. Brewer, R. Wester, M. Murcko, L. Frye, R. Farid, T. Lin, D.L. Mobley, W.L. Jorgensen, B.J. Berne, R.A. Friesner, R. Abel, Accurate and reliable prediction of relative ligand binding potency in prospective drug discovery by way of a modern free-energy calculation protocol and force field, Journal of the American Chemical Society, 137 (2015) 2695-2703.

[86] ADMET Predictor 8.5. http://www.simulations-plus.com/software/admetpredictor/ (last accessed May, 2018).

[87] G.M. Sastry, M. Adzhigirey, T. Day, R. Annabhimoju, W. Sherman, Protein and ligand preparation: parameters, protocols, and influence on virtual screening enrichments, Journal of computer-aided molecular design, 27 (2013) 221-234.

[88] Schrödinger Release 2018-1: Schrödinger Suite 2018-1 Protein Preparation Wizard; Epik, Schrödinger, LLC, New York, NY, 2016; Impact, Schrödinger, LLC, New York, NY, 2016; Prime, Schrödinger, LLC, New York, NY, 2018.

[89] N. Lallous, E. Leblanc, R.S. Munuganti, M.D. Hassona, N.A. Nakouzi, S. Awrey, H. Morin, M. Roshan-Moniri, K. Singh, S. Lawn, T. Yamazaki, H.H. Adomat, C. Andre, M. Daugaard, R.N. Young, E.S. Guns, P.S. Rennie, A. Cherkasov, Targeting Binding Function-3 of the Androgen Receptor Blocks Its Co-Chaperone Interactions, Nuclear Translocation, and Activation, Molecular cancer therapeutics, 15 (2016) 2936-2945. 


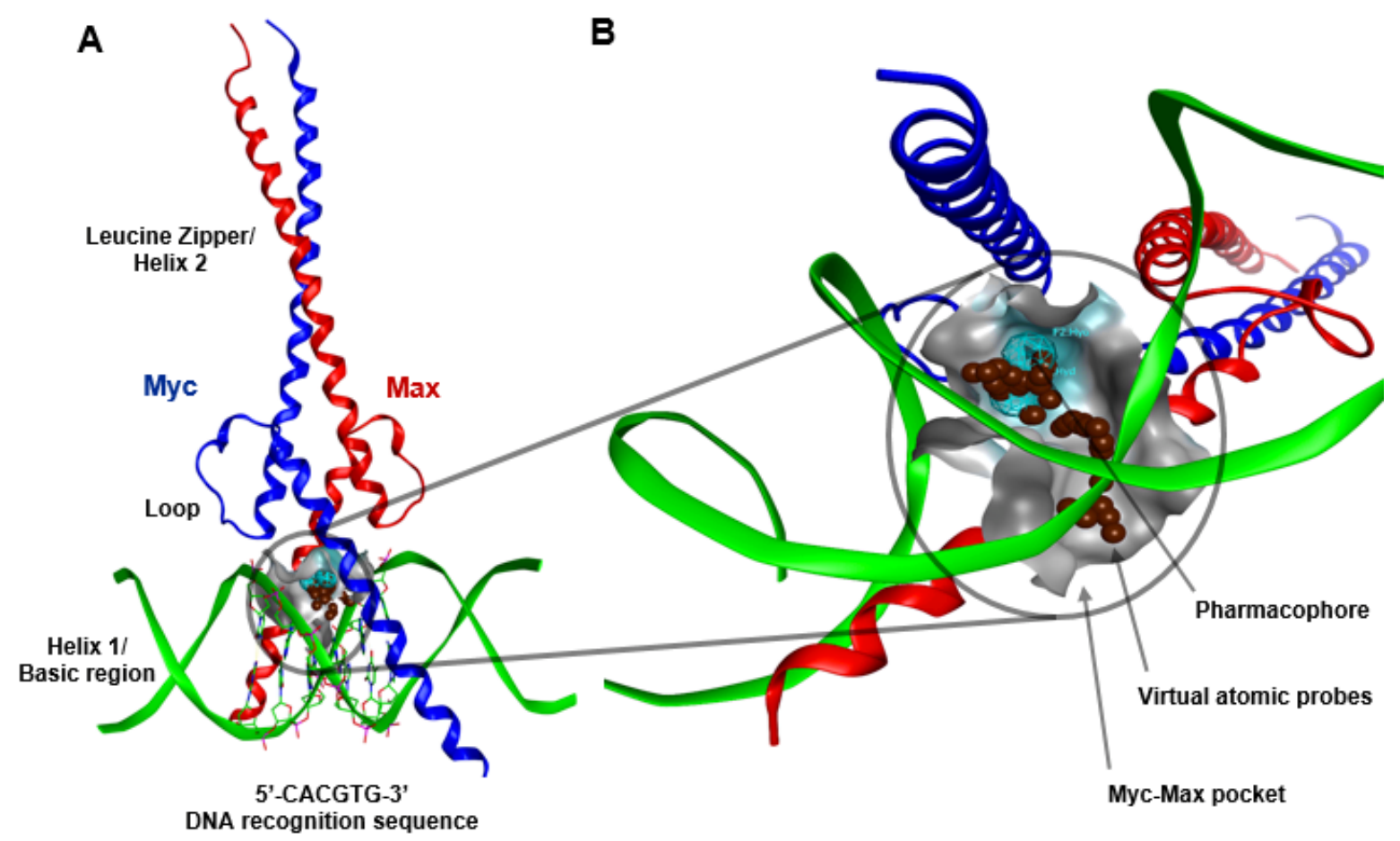

Fig. 1. (A) In silico model of the basic/helix-loop-helix/leucine zipper (bHLHZ) domain of Myc-Max bound to the 5'-CACGTG-3' DNA recognition sequence. The model was constructed based on the $1.9 \AA$ crystal structure of Myc-Max heterodimer in its bound form to the canonical E-box sequence (PDB ID: 1NKP). Myc (blue), Max (red) and the DNA backbone (green) are represented as ribbons. The DNA bases forming the E-box recognition sequence are represented as sticks. The Myc-Max predicted binding site at the DNA interface (side view) is represented as a grey solid surface and emphasized with a black circle; (B) Magnified view of the Myc-Max predicted binding site (bottom view of the structure of the complex in panel A which is rotated $90^{\circ}$ on the horizontal axis). The site was identified by probing the surface with virtual atoms (brown spheres within the pocket). The residues shaping the pocket are shown in the inset labelled in black and are further detailed in figure 4B. The pharmacophore utilized for subsequent virtual screening and filtering of potential binders is shown as cyan meshed spheres (see text for details). Inhibitors targeting the predicted site are expected to block Myc-Max binding to DNA. 
A

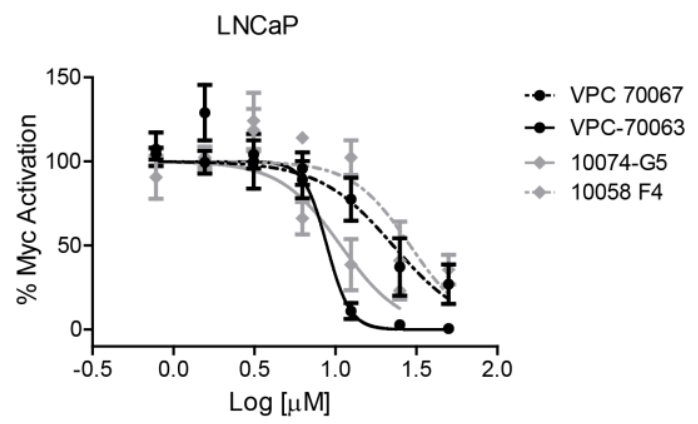

B
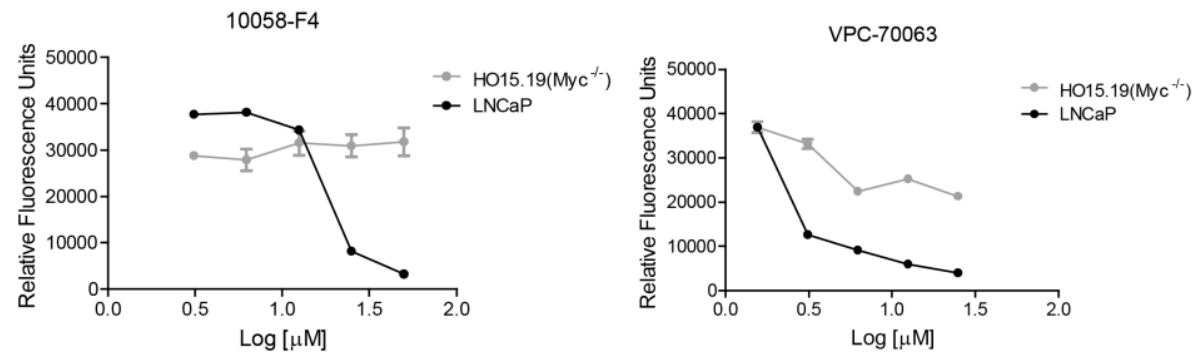

10074-G5
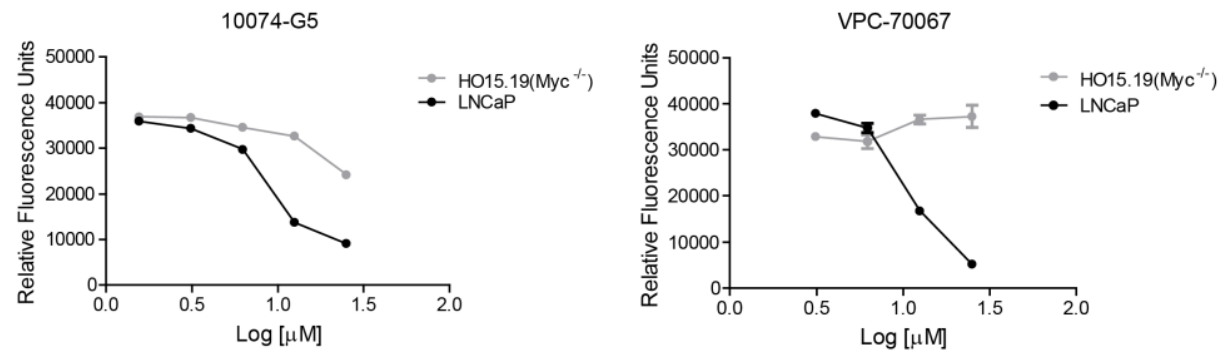

Fig. 2. (A) Dose response effect of selected hits in LNCaP PCa cells on c-Myc mediated luciferase activity. Literature inhibitors 10058 -

F4 and 10074-G5 were used as positive control. Data are presented as mean \pm SEM of triplicates and expressed as a percentage of luciferase activity relative to DMSO control. (B) The effect of VPC-70063 and VPC-70067 in comparison with 10058-F4 and 10074-G5 on cell viability of Myc positive ( $\mathrm{LNCaP}$ ) and Myc negative (HO15.19) cell lines. The percent of cell viability is plotted in dose dependent manner. Data points represent the mean \pm SD of three independent experiments performed in triplicate. 
A

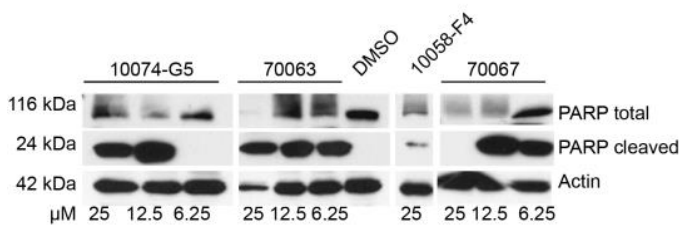

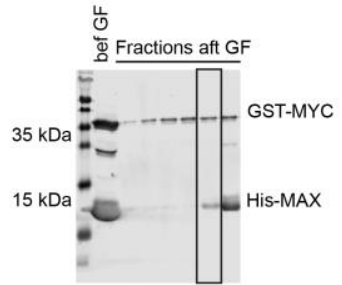

C

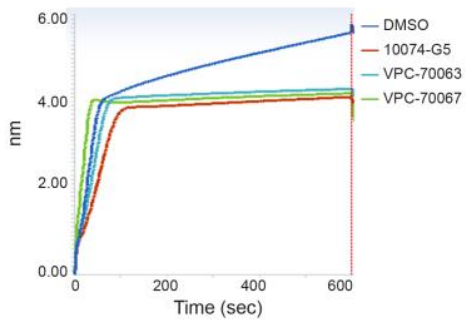

E
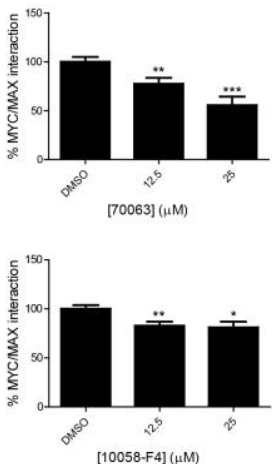

D
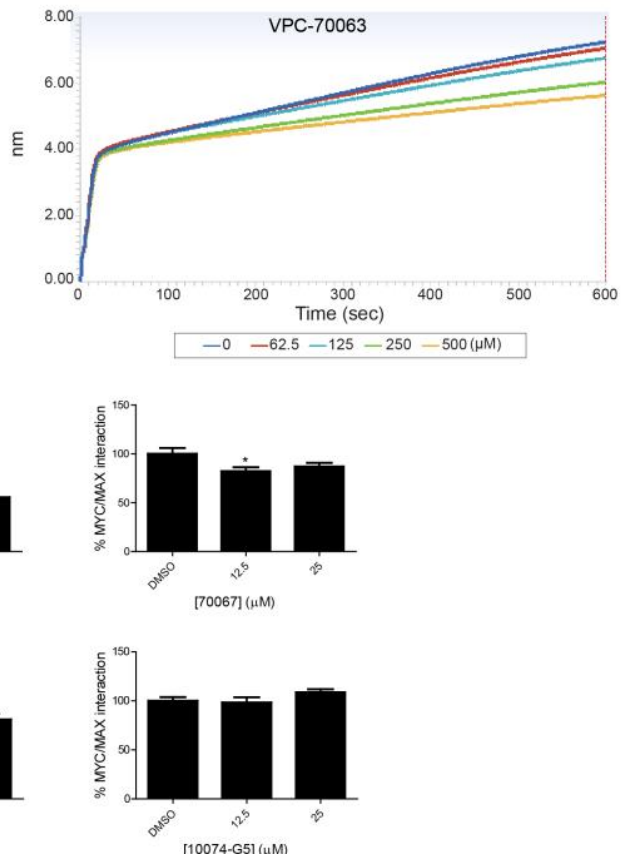

Fig. 3: (A) Inhibition of Myc with VPC-70067 and VPC-70063 resulted in apoptosis of LNCaP cells as indicated by cleavage of PARP in western blot. (B) Purification of GST-Myc and His-Max using size exclusion chromatography. The fraction highlighted with a black rectangle on the western blot corresponds to the fraction used for the binding assay. (C) Inhibition of Myc-Max interaction with the biotinylated E-box quantified by bilayer interferometry (BLI) in presence of $500 \mu \mathrm{M}$ of the studied compounds. (D) Dose response inhibition of Myc-Max binding to DNA in presence of our lead compound VPC-70063. (E) Mammalian 2-hybrid assay showing the effect of inhibitors on the interaction between Myc and Max. Data points represent the mean \pm SEM of at least three independent experiments. $\mathrm{P}<0.05(*), \mathrm{P}<0.01(* *)$ and $\mathrm{P}<0.001(* * *)$ were considered statistically significant compared with vehicle control (twotailed t-test). 
A

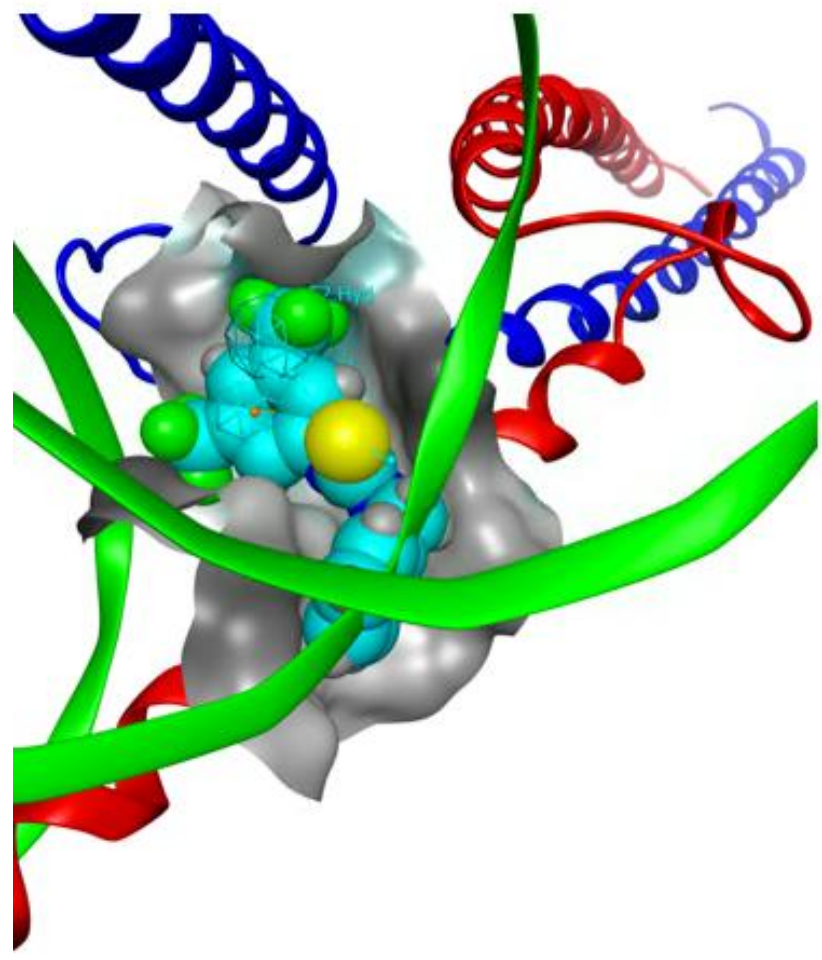

B

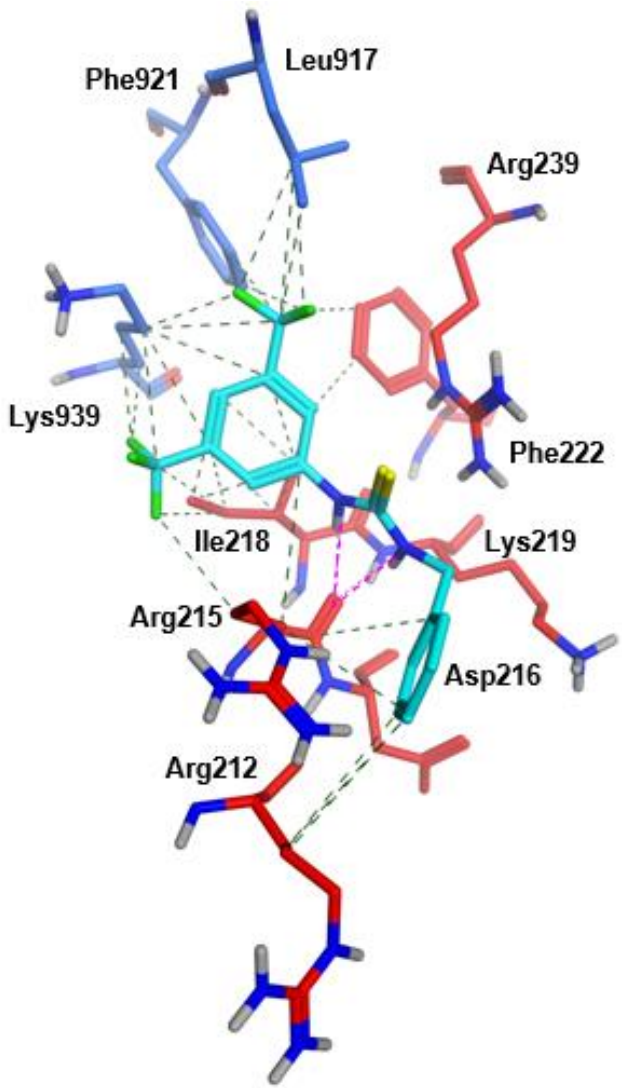

Fig. 4. (A) Predicted binding pose of VPC-70063 in space-filling representation within the Myc-Max DBD pocket $(\mathrm{cyan}=$ carbon, blue $=$ nitrogen, green $=$ fluorine, yellow $=$ sulfur $)$. Myc, Max, the DNA backbone and the pocket are colored using the same scheme as in figure 1. The chemical structure of VPC-70063 (1-benzyl-3-(3,5-bis(trifluoromethyl)phenyl)thiourea) is discussed in the text. The 3,5bis(trifluoromethyl)phenyl moiety of VPC-70063 is deeply buried in the hydrophobic core of the pocket. The benzyl ring of VPC-70063 significantly overlaps with the DNA backbone. VPC-70063 is expected to compete with DNA for binding to the Myc-Max DBD pocket; (B) Pocket residues predicted to interact with VPC-70063 at the Myc-Max DNA interface. Hydrogen bonds formed by the thiourea moiety of VPC-70063 are indicated with magenta dashed lines. Hydrophobic stabilizing interactions formed by the benzyl ring as well as the phenyl ring and the trifluoromethyl groups are represented with green dashed lines. Protein residue numbering follows that from the crystal structure of Myc-Max dimer (PDB ID: 1NKP; chains A, B). 
A

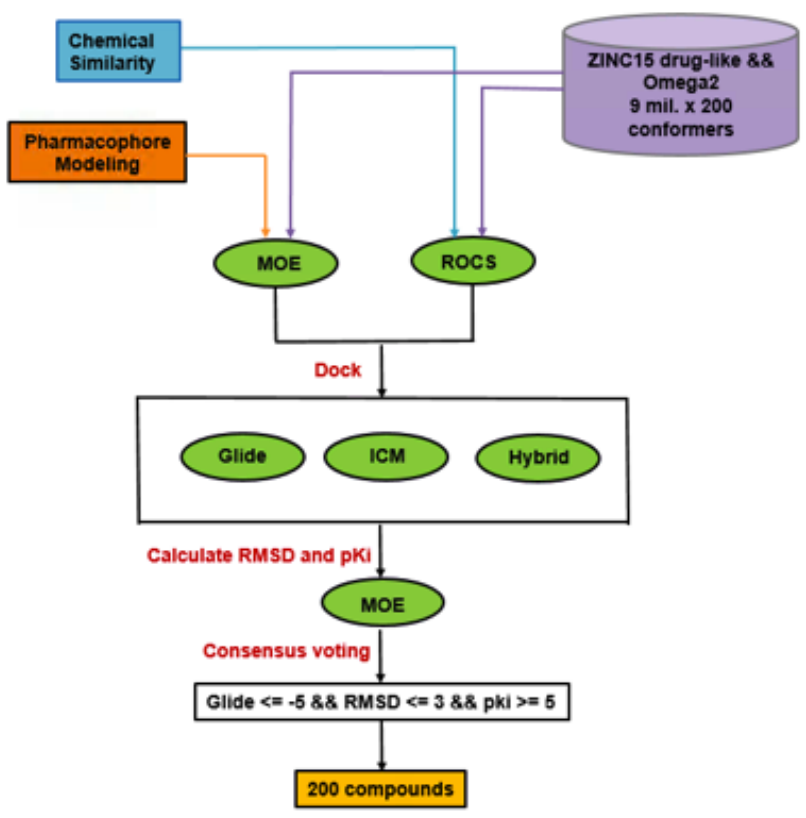

B

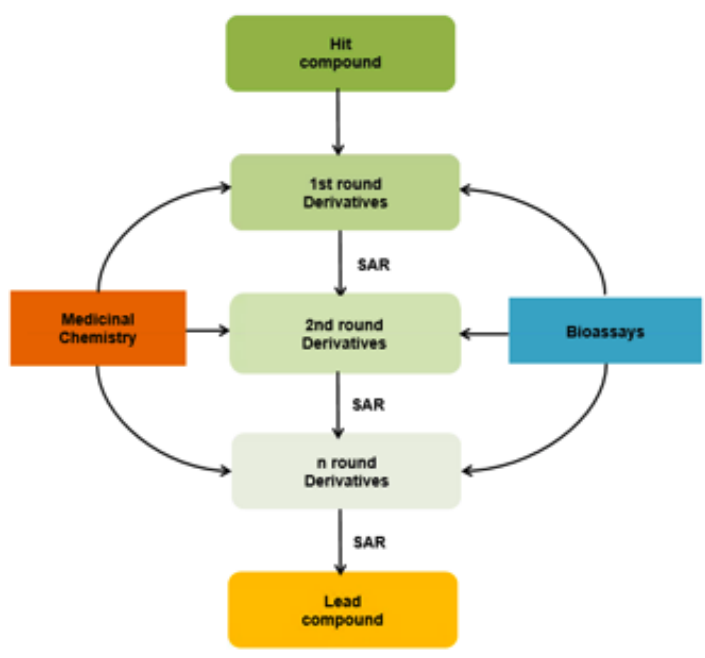

Fig. 5. (A) Virtual screening protocol implementing structure-based and ligand-based methodologies and consensus scoring for ranking and selection of analogs with potentially enhanced potency starting from initial hits. Using consensus voting based on docking scores, RMSD deviation between poses generated by various docking programs, calculated pKi and filtering using various thresholds, a small number of compounds can be selected for experimental testing from the millions at the start. (B) Lead optimization protocol consisting of iterative rounds of in silico modeling, medicinal chemistry and biological validation based on observed structure-activity relationships (SAR). Accurate prediction of relative binding free energy between hit and morphed derivatives obtained from free energy perturbation molecular dynamics simulations, as well as control of the ADMET profile of in silico constructed derivatives are state-of-the-art methods used for prioritization of derivatives for next iteration of SAR until a lead is found. 


\section{TABLE}

Table 1. Docking scores and activities of hit compounds that bind the ordered Myc-Max DBD at the identified site.

\begin{tabular}{|c|c|c|c|c|}
\hline \multirow[t]{6}{*}{ Compound ID } & Structure & Glide & Myc-Max & Myc- \\
\hline & & docking & transcriptional & Max/UBE2C \\
\hline & & score & activity & downstream \\
\hline & & $(\mathrm{kcal} / \mathrm{mol})$ & \%inhibition & pathway \\
\hline & & & $(25 \mu \mathrm{M})$ & \%inhibition \\
\hline & & & & $(25 \mu \mathrm{M})$ \\
\hline VPC-70005 & & -5.53 & 65 & $\mathrm{n} / \mathrm{a}$ \\
\hline VPC-70021 & & -5.63 & 95 & 73 \\
\hline VPC-70027 & & -5.69 & 53 & $\mathrm{n} / \mathrm{a}$ \\
\hline VPC-70033 & & -5.77 & 81 & 51 \\
\hline VPC-70053 & & -5.66 & 73 & 50 \\
\hline
\end{tabular}


31

VPC-70063

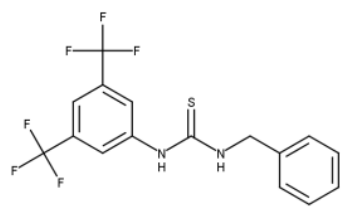

VPC-70064

VPC-70066
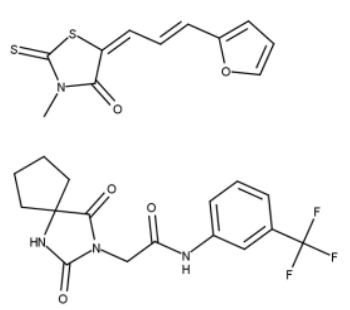

VPC-70067

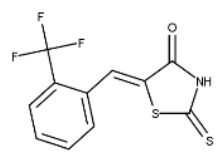

VPC-70068

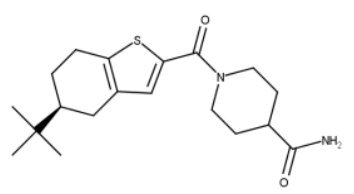

10058-F4

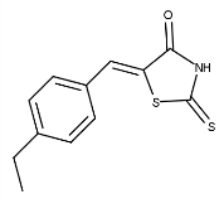

10074-G5

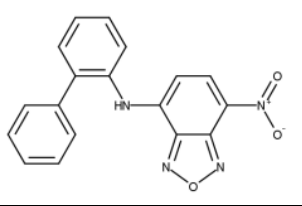

$-5.51$

106

94

$-5.59$

78

64

$-5.77$

65

$\mathrm{n} / \mathrm{a}$

$-5.67$

98

71

$-5.68$

73

58

n/a

91

70

n/a

88

$\mathrm{n} / \mathrm{a}$ 